\title{
ICT in Universities of the Western Himalayan Region of India: Study of Networks, Performance and Efficiency
}

\author{
Dhirendra Sharma \\ University Institute of Information \\ Technology, H.P.University, \\ Shimla 171 005, India
}

\author{
Vikram Kumar \\ University Institute of Information \\ Technology, H.P. University, \\ Shimla 171 005, India
}

\author{
Vikram Singh \\ Department of Computer Science \\ and Engg, Ch.Devi Lal University, \\ Sirsa, 125 055, India
}

\begin{abstract}
This paper presents a comparative study of performance and efficiency of various networks commissioned on different campuses of six universities in the western Himalayan region of India, within the framework of B- Node theory and its abstraction given by Cikara et al (2006). It has been done in three phases: i) The data handling capacity per user in the respective network has been presented and discussed in terms of the throughput of the core-switch and the efficiency of the network. ii) Using the efficiency parameters given by Cikara et al, for different nodes, efficiency of different networks have been found and compared among each other. iii) Finally, the segment/ component-wise efficiencies were measured for the real network system on the H.P. University campus, as a typical case, using JPerf software tool, which are compared with those given by Cikara et al. It was found that coupling factors play a vital role in the measurement of efficiency of the networks.
\end{abstract}

Keywords

Throughput, core switch, performance, efficiency, B-node theory

\section{INTRODUCTION}

In today's competitive world, ICT based development [1] namely the efficient Internet \& network system supported with reasonably broad bandwidth and well developed computer technology, has become indispensable to higher educational institutions for their effective functioning.

In a recent paper, an interesting approach of B-Node theory, as a measure of performance and efficiency of a network system, has been put forth by Cikara et al. (2006) [2]. Though variety of methods exist to predict the performance characteristics, where "rule of thumb" is subjective offering little mathematical rigor. The other stochastic modeling method uses complex mathematics, which can be problematic and tricky to understand and conceptualize. The approach of Bandwidth Nodes (B-Nodes) is found to be quite simple which is a high level bandwidthcentric abstraction used to decouple and simplify the complexity of a particular technology in which various devices can be modeled as an individual node or as a collection of nodes describing the overall function \& interactions between the subsystems and the operating environment. The approach demonstrates, to a first approximation, that the efficiency of BNodes can be decomposed and obtained as a product of all efficiencies contained within that node of the network system. This B-Node theory allows the performance and efficiency of a network to be easily and quickly determined, which will be closely followed in this paper.

Networking [3,4] allows one computer to send information to and receive information from another. To make it effective one has to seriously plan its architecture design, with a suitable topology, which may differ from place to place, in terms of multilayer switches within the framework of Open Systems Interconnection (OSI) model, as, outlined by ISO[5]. The OSI model divides network traffic into a number of layers each of which is independent of the layers around it. However, each layer builds on the services of the lower one while providing new services to the layer lying just above it. Such an abstraction allows a highly reliable protocol stacks known as TCP/ IP to function, which is an actual implementation of a layered communication network. This OSI model does not define protocols, but simply delegates each communication 'job' to a single layer within a well defined hierarchy. This is achieved with the help of high performance dynamic core switch.

In the context of transmission media technology, the Ethernet technology, (Metcalfe and Boggs 1972) [6] has been the most widely deployed network technology over the past three decades at the Global level due to its effectiveness and affordability in developing Local Area Network (LAN). However, Terra Byte or more Optical Fibre Cable (OFC) backbone supported with Giga Byte cable (CAT 6) within buildings for the desktop connectivity, have now become the most robust, reliable and tested solution. Such wired transmission media are being supplemented with the wireless (WiFi) technology in most of the research institutions.

One can classify network technologies as belonging to one of the two basic groups. One is LAN technologies which connect devices that are scattered around the campus having different buildings. Other is Wide Area Network (WAN) technologies which connects several LANs alongwith smaller number of devices that can be many kilometers apart. In comparison to WANs, LANs are faster and more reliable, but improvements in technology continue to blur the line of demarcation. Multimode and single mode Optical Fibre Cables (OFC) due to their inherent versatility, have allowed the network technologies to connect devices tens of kilometers apart, while greatly improving the speed, reliability and efficiency of both LAN and WAN. 
As per the recommendations of the IT Task force $[7,8]$ 'Technology Information Forecasting and Assessment Council' (TIFAC) established by Government of India in 1999, an educational institution has to develop its own infrastructure in the field of ICT, with an emphasis on:

i. To achieve high standards of academic excellence in the field of ICT providing a stimulating intellectual environment with the latest advances/ achievements in the field of research in different field.

ii. To promote creativity, problem solving capability and competence among students with ignited minds to make them first rate professionals in information technology and to make them sensitive to the problems faced by the society.

iii. To have an effective interaction among Universities and industry system in the country.

A decade after, another initiative has been taken by the Ministry of Human Resource Development (MHRD), New Delhi, during 2008-2009 under the National Mission on Education through Information Communication Technology (NMEICT)[1]. Its basic objective is to provide better connectivity among Universities/ Institutions/ Colleges in India, sharing e- material on education with the faculty and students of various educational institutions. Under this scheme, National Knowledge Network (NKN) is being setup through which all the universities are going to get connected with the internet facility having bandwidth of 1 Gbps and Virtual Private Network (VPN) is also being created to connect all the universities in the country. With this kind of initiative Bandwidth will not be any constraints with all the universities in the India.

Educause Centre for Applied Research (ECAR) conducted a survey in various states of USA, on the theme 'IT Networking in Higher Education' in 2005, whose findings and recommendations were found to be quite significant in the context of Campus Networking [9] of an institution. These may be summarized as follows:

- The University's mission and strategic directions set the context for the networking goals and vision, investment drivers and barriers to deliver network services. The goals were identified as reliable \& superspeed network to provide demand driven, leading- edge performance and best quality internet services to the academic/ research community.

- The existing wired network should be supplemented with the wireless (WiFi) network.
- $\quad$ in view of the complexity \& diversity of an Institution, the network should be managed by the institution and not by outsourcing.

- The transmission media technologies \& standards, bandwidth capacity, network architecture and redundancy all work in concert to ensure a network's scalability, reliability, fault tolerance, security and adaptability.

- The campus network should have full redundancy, specially at the core level, to ensure continued network availability.

- Network reliability is of increasing concern.

- Security has been a top barrier in providing network services.

- The network should have disaster recovery plan for data networking.

In view of these findings and the objectives set by MHRD, a live project was taken up on the campus of Himachal Pradesh University, Shimla, to have a network architecture design with a robust OFC backbone \& ethernet technology [10].

The objective of the present work is to carry out study in the following three steps,

- Study and analyse the performance \& efficiency of networks of different university campuses of the region using the technical details of switches given in Table I for core switches and the values given by Chikara et al. for a hypothetical network system.

- Using B-node theory as the base, we have investigated experimentally the performance and efficiency of the real network on the campus of H.P.University, Shimla.

- This experimental data was analysed, discussed and compared with that given by Cikara et al for a hypothetical network system.

\section{METHODOLOGY}

The mythology consists of the following steps:

- The Universities located in the western Himalayan Region of India are those spreading over the state of Himachal Pradesh and Jammu \& Kashmir. There are mainly seven universities located in this region out of which six ICT based universities have been selected purposely.

- Network data capacity per user as a measure of performance: In view of the fact that network data handling capacity can be calculated once the throughput of the core switch, efficiency of the network, may be in 
some approximation, and number of users are known. It may be taken as the simple empirical way of finding the performance. This is what will be taken up in this paper

- B-Node approach has been a simple method, in the first approximation, to find out the efficiency of the network, in the form of multiplication of individual nodes' (the main network components as abstractions) efficiencies, which Cikara et al has given as parameters for such abstractions. The method is supposed to be quite instructive to be used here.

- Finally, it was decided to consider an actual network architecture and find the experimental efficiency of various nodes (abstractions) within the framework of BNode theory, of a real system. For this, the network of H.P.University is chosen as a typical case, in the universities of Western Himalayan region of India.

- $\quad$ Since the efficiency experiment depends on several parameters (say coupling parameters) present in the network, a simple dependence on these parameters has been estimated approximately.

\section{TECHNICAL SUMMARY OF CAMPUS NETWORKS' ARCHITECTURE AND B- NODE THEORY:}

\subsection{Network Architecture}

The academic community in the state a brief outline of universities/ higher educational institutions had been facing challenges in respect of proper internet facility, bandwidth, Optical Fibre Backbone (OFB) and connectivity on the respective campuses for accessing the latest/ advanced material for research. Fortunately, almost around the year 1999, it was decided by the IT Task Force set up by Government of India that University Grants Commission (UGC) would provide complete connectivity through VSAT/Leased line (broadband services) to all the Indian Universities under UGC-Infonet Scheme through INFLIBNET, connecting all the libraries of the country. This decision was implemented within five years almost in all the universities funded by the UGC. However, the Optical Fibre Backbone on the campus and the internal networking within various departments/ buildings remained the responsibility of the respective universities. The universities of this region took the initiative to grab this golden opportunity to procure such a (LAN \& ICT) facilities within the stipulated time. Thus, with the availability of efficient network connectivity on the campuses, the dream of full fledged internet facility became a reality for accessing more than 4000 national and international online ejournals, to all the users on the campus.

Under the NMEICT, through NKN, the Universities got additional $10 \mathrm{Mbps}$ bandwidth. Complete details of the network architecture design, with star topology, of different universities has already been presented [11-12] by the authors. The relevant summary of the functional bandwidth, the active components of the network and the users of the ICT facility is given in Table 1.

Table 1. Present status of bandwidth, active components of the network and internet users in different universities of the region.

\begin{tabular}{|c|c|c|c|}
\hline S.No & Name & Bandwidth in 2010. & Active components and user details \\
\hline 1. & $\begin{array}{l}\text { H.P.Univeristy, Shiml } \\
\text { a }\end{array}$ & 10 Mbes $(1: 1)(\mathrm{NKN})$ & $\begin{array}{l}\text { Layer II - 26, Layer III- 3, Mutilayer } \\
\text { (Core switch)- 01, user } 900\end{array}$ \\
\hline 2. & $\begin{array}{l}\text { Jammu } \\
\text { University Jammu }\end{array}$ & $\begin{array}{l}30 \text { Mbps } 1: 1)+10 \\
\text { Mbps.(NKN) }\end{array}$ & $\begin{array}{l}\text { Layer II -40, Layer III(Core switch)- } \\
01 \text {, user } 900\end{array}$ \\
\hline 3. & NIT Hamirpur & $\begin{array}{l}64 \text { Mbpss }(1: 1)+1 \\
\text { Gbps (NKN) }\end{array}$ & $\begin{array}{l}\text { Layer II - 100, Layer III(Core switch)- } \\
03 \text {, user } 3000\end{array}$ \\
\hline 4. & JUIT, Solan & $\begin{array}{l}12 \mathrm{Mbps}(1: 1)+1 \\
\text { Gbps (NKN) }\end{array}$ & $\begin{array}{l}\text { Layer II - } 75 \text { Layer III(Core switch)- } \\
01 \text {, user } 2500\end{array}$ \\
\hline 5. & $\begin{array}{l}\text { Agricultural Univ. } \\
\text { Palampur }\end{array}$ & $2 \mathrm{Mbps}(1: 1)$ & $\begin{array}{l}\text { Layer II - 10, Layer III(Core switch)- } \\
01 \text {, user } 450\end{array}$ \\
\hline 6. & $\begin{array}{l}\text { Horticultural Univ. } \\
\text { Nauni, Solan }\end{array}$ & $4 \mathrm{Mbps}(1: 1)$ & $\begin{array}{l}\text { Layer II - 08, Layer III(Core switch)- } \\
01 \text {, user } 300\end{array}$ \\
\hline
\end{tabular}

Almost all the six universities tried to have an efficient Network Architecture, by including the following essential elements:

- $\quad$ Effective Topology, transmission media, high power core switch and routing switches.

- Sufficient Internet bandwidth capacity.

- Security architecture.

The important features of the most crucial part of the network architecture i.e. the high power core switch, are given in Table 2 ., as some of the features like throughput, will be utilized in calculating the efficiency and the performance of the network.

Table 2. Comparative technical features of Core switches

\begin{tabular}{|c|c|c|c|c|c|c|}
\hline$F=0$ & $\begin{array}{l}3 \operatorname{com} 750 \\
\text { H.P.US Simla }\end{array}$ & \begin{tabular}{|l|} 
Cisco \\
C4507K \\
Jammu \\
\end{tabular} & $\begin{array}{l}\text { D Link } \\
\text { DE S3828 } \\
\text { CS KV.Palampur }\end{array}$ & $\begin{array}{l}\text { DGS3312SR } \\
\text { Nauri Uriv. }\end{array}$ & $\begin{array}{l}3 \text { Com } 4060 \\
\text { J.P.Uriversity }\end{array}$ & \begin{tabular}{|l|} 
Aleatel \\
$\mathbf{8 g 0 0}$ \\
HIT \\
Hamizpux \\
\end{tabular} \\
\hline $\begin{array}{l}\text { Higher Performance core } \\
\text { Switch } \\
\text { Back Plane/Switching } \\
\text { capacity (Gb ps) }\end{array}$ & 11. F. O S nutula & 2 & 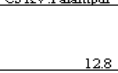 & A9 & 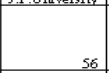 & Rartuspur \\
\hline $\begin{array}{l}\text { Masimum azeregate system } \\
\text { througlput (Mpps) } \\
\text { Laver II Switch }\end{array}$ & 179 & 48 & 10 & 17 & 40 & 240 \\
\hline $\begin{array}{l}\text { Laver III Switch } \\
\text { No. of MAC address } \\
\text { Support } \\
\text { Static MAC Address } \\
\text { Support }\end{array}$ & $\begin{array}{r}16000 \\
5000\end{array}$ & $\begin{array}{l}32000 \\
10000\end{array}$ & $\begin{array}{r}16000 \\
4000\end{array}$ & $\begin{array}{r}10000 \\
5000 \\
\end{array}$ & $\begin{array}{r}12000 \\
3000 \\
\end{array}$ & $\begin{array}{l}64000 \\
10000\end{array}$ \\
\hline No. of VLAN S upport & 4096 & 1023 & 4096 & 4000 & 30 & 4096 \\
\hline $\begin{array}{l}\text { Junbo Frames Support } \\
\text { (bytes) }\end{array}$ & 9000 & 9000 & 9000 & 9000 & 9000 & 9000 \\
\hline Bandwidth capacity $\left(\mathrm{Mb}_{\mathrm{p}} \mathrm{s}^{-}\right)$ & 1001000 & 100 & 100 & 100 & 100 & $100 / 1000$ \\
\hline $\begin{array}{l}\text { Layer III Swith } \\
\text { Dymamic poutes }\end{array}$ & 64000 & 32000 & 2000 & 2000 & 2000 & 65000 \\
\hline $\begin{array}{l}\text { Static Routes } \\
\text { Address resolution Protocol } \\
\text { (ARP) extries }\end{array}$ & $\begin{array}{l}5000 \\
8000\end{array}$ & $\begin{array}{r}10000 \\
8000 \\
\end{array}$ & $\begin{array}{r}128 \\
4000 \\
\end{array}$ & $\begin{array}{r}256 \\
4000 \\
\end{array}$ & $\begin{array}{r}100 \\
5000 \\
\end{array}$ & $\begin{array}{l}5000 \\
5000\end{array}$ \\
\hline IP Interfaces & 1024 & 64 & 64 & so & 64 & 20000 \\
\hline $\begin{array}{l}\text { Bandwrid th capacity }\left(\mathrm{Mb}^{\mathrm{s}}\right) \\
\text { Feature }\end{array}$ & 1000 & 1000 & 1000 & 1000 & 1000 & 1000 \\
\hline $\begin{array}{l}\text { Link Aggregation } \\
\text { Spanning Tree Support }\end{array}$ & \begin{tabular}{|l|} 
IEEE \\
802.3 ad \\
Yes \\
\end{tabular} & \begin{tabular}{|l|l|} 
FEEE \\
$\$ 023$ ad \\
Yes \\
\end{tabular} & $\begin{array}{l}\text { IEEE 802.3ad } \\
\text { Yes }\end{array}$ & $\begin{array}{l}\text { IEEE } \\
\text { 802.3ad } \\
\text { Yes }\end{array}$ & \begin{tabular}{|l|} 
IEEE \\
802.3 ad \\
No \\
\end{tabular} & \begin{tabular}{|l} 
FEE \\
$802.3 \mathrm{ad}$ \\
Yes \\
\end{tabular} \\
\hline Redund ant Power Supply & Yes & \begin{tabular}{|l|} 
Yes \\
\end{tabular} & Yes & Yes & Yes & Yes \\
\hline Console & Ye & Yes & Yes & Yes & No & Yes \\
\hline & & & Yes & 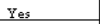 & & \\
\hline RMON & Yes & Yes & Yes & Yes & Yes & Yes \\
\hline & No & No & Yes & $\mathrm{Ye}_{\mathrm{e}} \mathrm{rat}$ & Yes & Yes \\
\hline $\begin{array}{l}\text { Port Monitoing } \\
\text { Sys log }\end{array}$ & \begin{tabular}{|l} 
Yes \\
Yes \\
\end{tabular} & \begin{tabular}{|l} 
No \\
Yes
\end{tabular} & $\begin{array}{l}\text { Yes } \\
\text { Yes }\end{array}$ & $\begin{array}{l}\text { Yes } \\
\text { Yes }\end{array}$ & \begin{tabular}{|l} 
No \\
Yes
\end{tabular} & $\begin{array}{l}\text { Yes } \\
\text { Yes }\end{array}$ \\
\hline $\begin{array}{l}\text { 802.1p Prionity Tazging } \\
\text { DifServ Qos }\end{array}$ & $\begin{array}{l}\text { No } \\
\text { No }\end{array}$ & $\begin{array}{l}\text { No } \\
\text { No }\end{array}$ & $\begin{array}{l}\text { Yes } \\
\text { Yes }\end{array}$ & $\begin{array}{l}\text { Yes } \\
\text { Yes }\end{array}$ & $\begin{array}{l}\text { No } \\
\text { Yes }\end{array}$ & $\begin{array}{l}\text { Yes } \\
\text { Yes }\end{array}$ \\
\hline Multi Layer Access Lis & No & No & No & Yes & No & Yes \\
\hline & & & & & & \\
\hline MAC based Authent & No & No & Yes & Yes & Yes & Yes \\
\hline VLA & Yes & Yes & Yes & Yes & Yes & Yes \\
\hline MP Snooping & $\mathrm{Ye}_{\mathrm{e}}$ & No & $\mathrm{Ye}_{\mathrm{e}}$ & $\mathrm{Ye}_{\mathrm{e}}$ & & \\
\hline
\end{tabular}




\section{B-Node Theory:}

Cikara et al (2006) used a hypothetical network on the basis of which they developed a simple method 'B-Node theory', of reducing the total network into different individual abstractions for calculating efficiency, to a first approximation. Their findings of efficiency parameters of different important abstractions like Internet Protocol (IPv4), device (PC- PC), switches (L-2 and L3 ) and the multi layer core switch in the network system, are summarized in Table 3.

Table 3. Efficiency parameters for various $B$-nodes in the network (Cikara et al, 2006).

\begin{tabular}{|c|c|c|}
\hline \multicolumn{3}{|c|}{ Efficiency parameter for various B-Nodes } \\
\hline $\mathrm{e}_{\text {ip }}$ & eipu4 & 0.9493 \\
\hline epc-pc & $\mathrm{PC}-\mathrm{PC}$ & 0.9978 \\
\hline $\mathrm{e}_{\mathrm{LII}}$ & LII Switch & 0.9997 \\
\hline ELII & LIII Switch & 0.6683 \\
\hline $\begin{array}{l}\text { ess (assumed at } \\
\text { highest end) }\end{array}$ & $\begin{array}{l}\text { Core Switch } \\
\text { (Multilayer) }\end{array}$ & 0.6683 \\
\hline
\end{tabular}

$\mathrm{e}_{\mathrm{ip}}=$ Efficiency of IPv4, $\mathrm{e}_{\mathrm{pc}-\mathrm{pc}}=$ Efficiency of PC to PC communication, $\mathrm{e}_{\mathrm{LII}}=$ Efficiency of layer- 2 switches, $\mathrm{e}_{\mathrm{LIII}}=$ Efficiency of Layer- 3 switch. $\mathrm{e}_{\mathrm{cs}}=$ Efficiency of core/ multiplayer switch taken at higher end.

Using these values, the net efficiency, e, of the complete network system can be obtained as a multiplication of respective efficiencies, $e_{i}$, of different abstractions (Table 3.), where $i$ denotes the number of abstractions i.e.

$$
\mathrm{e}=\prod_{\mathrm{i}=1}^{\mathrm{n}} \mathrm{e}_{\mathrm{i}}
$$

\section{PERFORMANCE \& EFFICIENCY OF NETWORKS}

The throughput of the core switch alongwith other technical details has already been mentioned in Table I. The calculation of performance efficiency, using B- node theory, of networks laid in configuration Tier II or Tier III in different universities, has been taken up in two steps.

- Once the maximum throughput of the core switch is known, the data handling capacity/ user has been calculated and presented in Table 4. In this process we have used the efficiency parameters of Cikara et al, to determine the total efficiency of the campus networks.

- It was further tempting to attempt finding the experimental values of efficiencies of different abstractions as done by Cikara et al, on a real functional network system. The authors considered a typical case of the network architecture of H.P.University and found the experimental values presented in Table 5a.

4.1. Data- handling Capacity per User : The results of the total efficiency and the data handling capacity per user, are given in Table 4.
Table 4. Actual throughput, efficiency and data handling capacity per user of the network in different universities.

\begin{tabular}{|c|c|c|c|c|c|c|}
\hline S.No & HPU & $\begin{array}{l}\text { Jammu } \\
\text { Uni }\end{array}$ & NIT & JPU & Palampur & Nauni \\
\hline Tier system & III* & II** & II & II & II & II \\
\hline $\begin{array}{l}\text { Theoretical Throughput (T)/ } \\
\text { Backplane of Switch in (Gbps) }\end{array}$ & 96 & 64 & 512 & 56 & 12.8 & 24 \\
\hline $\begin{array}{l}\text { Efficiency (e) of The network as } \\
\text { per B- Node theory (in } \% \text { ) }\end{array}$ & 42.29 & 63.28 & 63.28 & 63.28 & 63.28 & 63.28 \\
\hline $\begin{array}{l}\text { Actual User Data (D) Handing } \\
\text { Network capacity (Gbps) D= } \\
\text { (E*T)/100 }\end{array}$ & 40.60 & 40.49 & 323.99 & 35.44 & 8.10 & 15.19 \\
\hline No. of users (U) & 900 & 900 & 3000 & 2500 & 450 & 300 \\
\hline $\begin{array}{l}\text { Data Handing Network Capacity } \\
\text { per user= (D/U)*1024 (Mbps) }\end{array}$ & 46.19 & 46.08 & 110.59 & 14.51 & 18.43 & 51.84 \\
\hline
\end{tabular}

In Table 2., theoretical values of throughput/backplane of switches have been mentioned. These values were taken from the respective technical sheets of different products provided by the vendors. In Table 3. the efficiency parameters for various nodes of a network has been defined by Cikara et al. The actual user data handling capacity of the network has been calculated with the help of efficiency parameters of B- Node theory, and presented them in Table 4. and graphically in Fig.1.

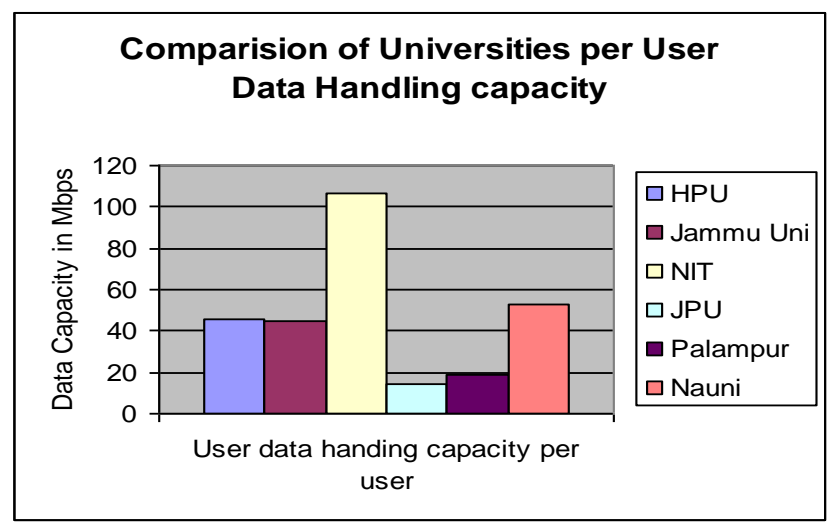

Fig. 1. Data Handling Network Capacity per user of different universities

NIT Hamirpur is having the highest data handling capacity per user, with a value of $110.59 \mathrm{Mbps}$, followed by HU Nauni (51.84 Mbps), H.P.University (45.5\%), Jammu University (45\%), AU Palampur (18.8\%) and then J.P University (14.2\%). For NIT Hamirpur, it is a very good network data handling capacity even after having such a large no of users on the campus. Whereas Nauni stand $2^{\text {nd }}$ even after having obsolete model of the core switch having a very low backplane of 24 Gbps. HP University Stands at No.3 with having network data handling capacity of 45.55 Mbps. Jammu University is at No. 4 having data handling capacity of $44.98 \mathrm{Mbps}$. The J.P.University, which is one of the best technical universities, found to be lowest in network data handling capacity per user.

\subsection{Efficiency Measurement on a Real Network system of H.P. University, Shimla.}

An experiment has been performed on real time network system, considering a typical case of Himachal Pradesh University, Shimla, based on different network segments available on campus network using the basic concept of For this experiment, 
JPerf v.2.0.2 [13] (a graphics version of iperf), software tool has been used for measuring TCP and IPv4 values between two end points of different segments on H.P.University Campus network. The segment wise efficiency on real network of H.P.University, Shimla as a typical case, is being presented in Table 5a.

Table 5a.: Experimental efficiency on the real network of H.P.University, Shimla.

\begin{tabular}{|c|c|c|c|c|c|}
\hline Segment & $\begin{array}{l}\text { A } \\
\text { Theoretical } \\
\text { Maximum } \\
\text { (Mh/s) } \\
\text { (Cikara et } \\
\text { al) } \\
\text { (I) }\end{array}$ & $\begin{array}{l}\text { B } \\
\text { Respective } \\
\text { output } \\
\text { (Mb/s) } \\
\text { (II) }\end{array}$ & $\begin{array}{l}\text { (E) } 1 \text { Segment- } \\
\text { wise efficiency } \\
(\%) \\
\mathrm{E}=\mathrm{B} / \mathrm{A} * 100 \\
\text { (III) }\end{array}$ & $\begin{array}{l}\text { Remarls } \\
\text { (Dependent on } \\
\text { factors) } \\
\text { (IV) }\end{array}$ & $\begin{array}{l}\text { Efficiency } \\
\text { of Nodes } \\
\text { from } \\
\text { Cikara et al } \\
\text { (V) }\end{array}$ \\
\hline PC-PC & 949.3 & 877.1 & 92.39 & Configuration of $\mathrm{PC}^{\prime}$ 's & 99.78 \\
\hline PC-LII-PC * & 949.3 & 380.4 & 40.07 & $\begin{array}{l}\text { LII } 100 \text { Mbps speed. } \\
\text { (Limitation) }\end{array}$ & 99.97 \\
\hline PC-LIII-PC & 949.3 & 790.6 & 83.28 & $\begin{array}{l}\text { LIII } 1000 \mathrm{Mbps} \\
\text { speed. }\end{array}$ & 66.83 \\
\hline $\mathrm{PC}-\mathrm{CS}-\mathrm{PC}$ & 949.3 & 866.8 & 91.31 & CS 1000 Mbps speed & 66.83 \\
\hline
\end{tabular}

The comparison of segment wise efficiencies, experimental vs. Cikara et al, is plotted in Fig 2.

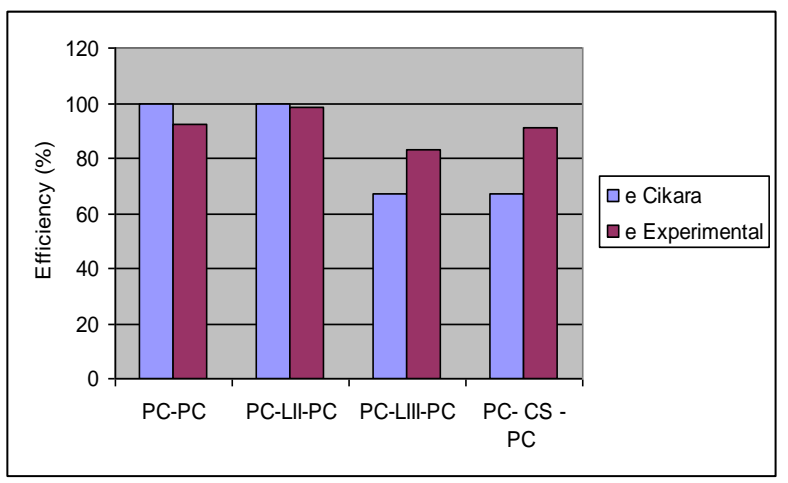

Fig. 2. Comparison of efficiencies, experiment values from H.P.U's real network system vs those of Cikara et al..

It may be mentioned before a comparative analysis is carried out that most of the active \& passive components in the HPU network are having the Gbps capacity except the LII switch which has the capacity $100 \mathrm{Mbps}$ only. In star topology, when LII is used in the circuit (in series) then the following equation. [14] becomes effective:

$\mathrm{B}_{\text {circuit }}=\operatorname{Min}\left\{\mathrm{B}_{1}, \mathrm{~B}_{2}, \mathrm{~B}_{3} \ldots . \mathrm{B}_{\mathrm{n}}\right\}$

Where $B_{\text {circuit }}$ is the effective bandwidth and $B_{n}$ corresponds to the Bandwidth of nth component of the network system.

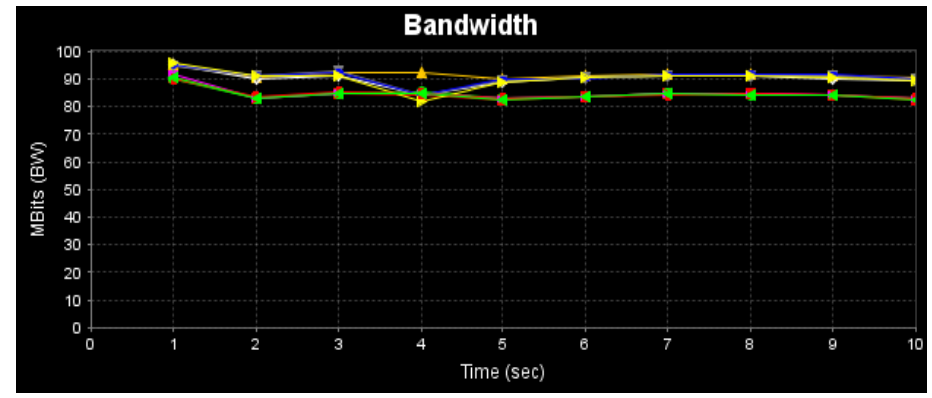

Figure 3. Two ends with PC-Core switch-PC.
In Figure 3, experimental value has been shown, which clearly shows that bandwidth between two end points is given as 866.8 $\mathrm{Mb} / \mathrm{s}$ for a typical case of PC-Core Switch-PC. This value is also given in Table 5a.

This data may be analysed as follows:

- $\quad$ Following Fig 2, last two components i.e. PC-LIIIPC and PC-CS-PC reveal the higher value of efficiencies as expected because of higher processing capacities/ speed of Devices used as compared to the devices used by Cikara et al.

- $\quad$ PC-PC component is less than Cikara et al due to PC- dependent factors.

- $\quad$ PC-LII-PC is found to be little less than Cikara et al due to a mixed link capacity (1 Gbps LAN Cards and 100 Mbps LII switching), where eq. (2) plays its role effectively.

- A 'negative bandwidth' [14] (decrease in bandwidth), was observed after the processing took place.

- In principle, all the components of the network [15] should be of the same link capacity for a reasonable comparison. The mixing of nodes with different capacities is bound to lower the efficiency of the circuit.

\subsection{Experimental Values towards B-Node Theory on} Real Network.

In order to study the effect of B-Node theory on real network, an experiment was conducted. For this different experimental measurements has been taken using components of real functional network as given in table $5 \mathrm{~b}$.

Table 5b. Experimental value of efficiency, component wise.

\begin{tabular}{|l|l|c|}
\hline S.NO & Component & Experimental Maximum efficiency (Mh/s) \\
\hline A & PC-PC & 0.9239 \\
\hline B & Core switch (7750 3 COM) & 0.9882 \\
\hline C & $\begin{array}{l}\text { Layer III } \\
\text { (55003 Com })\end{array}$ & 0.9013 \\
\hline D & $\begin{array}{l}\text { L-II } \\
\text { (44003 Com) }\end{array}$ & 0.4007 \\
\hline
\end{tabular}

Table 5 c. Comparison of efficiencies, experimental vs theoretical.

\begin{tabular}{|l|c|c|c|c|}
\hline Segment & $\begin{array}{l}\text { Eq.(1) from B- } \\
\text { node Theory } \\
\text { and Values } \\
\text { from Table 5b. } \\
\text { (I) }\end{array}$ & $\begin{array}{l}\text { Experimental } \\
\text { Efficiency from eq } \\
\text { (1) } \begin{array}{l}\text { (1) B-node Theory, } \\
\text { and values from } \\
\text { Table 5b. } \\
\text { (II) }\end{array}\end{array}$ & $\begin{array}{l}\text { Experimental } \\
\text { Efficiency for the } \\
\text { entire segment } \\
\text { on real network } \\
\text { (III) }\end{array}$ & $\begin{array}{l}\text { Relative error due } \\
\text { to the coupling } \\
\text { factor in real } \\
\text { network } \\
\text { (II-III) }\end{array}$ \\
\hline PC-CS-PC & $\mathrm{A}^{*} \mathrm{~B}$ & 0.9129 & 0.8465 & 0.0784 \\
\hline PC-CS-LIII-PC & $\mathrm{A}^{*} \mathrm{~B}^{*} \mathrm{C}$ & 0.8228 & 0.8061 & 0.0207 \\
\hline PC-CS-LIII-LII-PC & $\mathrm{A}^{*} \mathrm{~B}^{*} \mathrm{C}^{*} \mathrm{D}$ & 0.3297 & 0.3279 & 0.0054 \\
\hline
\end{tabular}

The analysis of experimental efficiencies (B-Node approach vs Actual observed), based on the Table $5 \mathrm{c}$, is given below: 
- From Table $5 \mathrm{c}$, it is pertinent to mention that the values obtained in column II and III, are quite comparable, proves that $\mathrm{B}$ node theory is also applicable for real functional networks.

- However, the relative error in the expected vs actual efficiency on a particular segment, using Jperf 2.0.2, software tool, is given in the last column, which is around $5 \%$.

- $\quad$ This difference may be attributed to the fact that abstraction depends on coupling factors through which the data is passing.

- The role of LII seems like a bottleneck in whole of this experiment, may be because of its noncompatibility.

- These results should be seen in the context of BNode approach which is supposed to be valid as a first approximation

\section{CONCLUSIONS}

This paper presents a comparative study of performance, efficiency and utilization of the bandwidth in terms of data handling capacity per user in the university environment of western Himalayan region of India. Further, the experimental efficiency (component wise) has been determined for a typical case of real, functional network system of H.P. University, Shimla, which has been compared with that obtained from the Bnode theory.

Conclusions of this work are as follows:

- In order to have the maximum efficiency, link capacity of all the active and passive components of network systems should have consistent values i.e. Gbps or higher and must be compatible with each other. Mixing different link capacities of various components is found to decrease the efficiency of total network system.

- The efficiency of the network architecture design is found to depend mainly on throughput, different level switches in different tiers, PC- PC link, the internet protocol (ip, LII,\& LIII) and finally on the number of users on the campus. The universities should try to optimize the efficiency of their network system .

- The B-Node theory may be used as a measure of performance \& efficiency, to a first approximation, of the real functional networks. The difference in the expected efficiency (as per the B-Node theory) and the actual values of a real network system is found to depend upon different coupling factors involved in the actual network segments/components.

- $\quad$ B-Node theory may be very helpful in evaluating the options before the implementation of network architecture design on the campus, for having an efficient, reliable, secure and compatible 'Nodes' of the network so as to meet the demand of users

\section{ACKNOWLEDGMENT}

The authors gratefully acknowledge the cooperation and help from UGC, New Delhi and INFLIBNET, Ahmedabad.

\section{REFERENCES}

[1] NMEICT- Mission Document (www.education.nic.in/dl/MissionDocument.pdf)

[2] Cikara, S, Maj, S P and Shaw DT 2006, "Modeling Layer 2 and Layer 3 Device Bandwidths using B Nodes Theory, proceeding of Twenty-Ninth Australasian Computer Society Conference (ACSC2006)

[3]Tanenbaum, A., Computer Networks, Upper Saddle River, N.J., Prentice Hall, $4^{\text {th }}$ Edition, 2003

[4]James F. Kurose and Keith Ross, Computer Networking- A Top-Down Approach Featuring the Internet, $5^{\text {th }}$ Edition, Pearson Education, 2010.

[5] http://standards.iso.org

[6] Metcalfe Robert M. and Boggs David R. (1975), Ethernet: Distributed Packet Switching for Local Computer Networks, CSL.

[7] Kalam, A.P.J. and Rajan, Y.S., India 2020- A Vision for the New Millennium (Viking, 1998)

[8] Kalam A.P.J. and Pillai, A.S., Envisioning an Empowered Nation (Tata McGraw Hill Publishing Co. Ltd, 2004)

[9] Hawkins, B.L. et al., EDUCAUS Core Data Services 2003 Summary Report (EDUCAUSE 2004)

[10] Sharma, Dhirendra and Singh Vikram, ICT in Universities of the. Western Himalayan Region of India: Networking and Architecture Design- A Comparative Study. IJAEA, June Vol 1. 2010.

[11] Sharma Dhirendra and Singh Vikram (2007), Campus wide Networking in H.P.University, Shimla, A Live Project, proceedings.

[12] Sharma. Dhirendra and Singh Vikram (2010), "ICT in Universities of the Western Himalayan Region of India II: A Comparative SWOT analysis" IJCSI Vol 7, issue 1, No 3, pp 62 72, January 2010.

[13] http://code.google.com/p/xjperf/downloads/list

(for downloading Jerf Softpware tool)

[14] Veal, D., G. Kohli, S. P. Maj and J. Cooper (2005). A Framework for a Bandwidth Based Network Performance Model for CS Students. 2005 ASEE Annual Conference and Exposition "The Changing Landscape of Engineering and Technology Education in a Global World", Portland, Oregon.

[15] Bjornsen,A., in IT Networking in Higher Education; Campus Network, Ch 4, ECAR Research Study 2 (2005) page 31 , and references therein. 